\title{
Correction to: Dysregulated expression of long noncoding RNAs serves as diagnostic biomarkers of type 2 diabetes mellitus
}

Weiyue Zhang ${ }^{1} \cdot$ Juan Zheng ${ }^{1} \cdot$ Xiang Hu$^{1} \cdot$ Lulu Chen $^{1}$

Published online: 20 August 2019

(c) Springer Science+Business Media, LLC, part of Springer Nature 2019

\section{Correction to: Endocrine}

https://doi.org/10.1007/s12020-019-02015-7

The article Dysregulated expression of long noncoding RNAs serves as diagnostic biomarkers of type 2 diabetes mellitus, written by Lulu Chen, was originally published electronically on the publisher's internet portal (currently SpringerLink) on 25 July 2019 with open access. With the author(s)' decision to step back from Open Choice, the copyright of the article changed on August 2019 to () Springer Science+Business Media, LLC, part of Springer Nature 2019 and the article is forthwith distributed under the terms of copyright.

The Original article has been corrected.

The original article can be found online at https://doi.org/10.1007/ s12020-019-02015-7.

Lulu Chen

cheria_chen@126.com

1 Department of Endocrinology, Union Hospital, Tongji Medical College, Huazhong University of Science and Technology, 430022 Wuhan, China 